\title{
Crust-movements connected with Tango (Japan) Earthquake of I927.
}

TN no other earthquake have the movements of the Tango earthquake of Mar. 7, 1927. In several

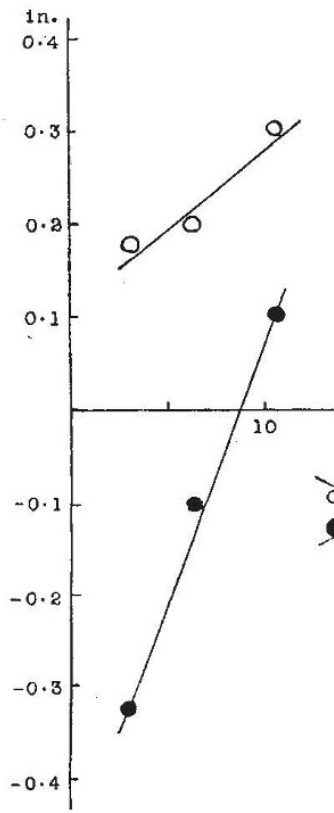

districts, such as those of the Californian earthquake of 1906 or the Kwanto earthquake of 1923, the series of levellings have been repeated once, but after the Tango earthquake they have been repeated again and again, with a lavish expenditure of trouble for which seismologists are deeply indebted, to the Land Survey Department of the Imperial Japanese Army. Series of precise levellings were carried out during April-June, JuneJuly 1927, Mar.-April 1928, and Aug.-Oct. 1929, while the re-triangulation of the central district was made during May-June, Aug.Sept., and Oct.-Nov. 1927, and April-Sept. 1928. The results of the repeated measurements have been studied by Prof. C. Tsuboi, of the Earthquake Research Institute, in an admirable series of papers published in the Bulletin of the Institute (vol. 6, pp. 71-83; 1929 ; and vol. 8 , pp. 153-220, $338-345 ; 1930)$.

The first of these memoirs is confined to the of the blocks in some cases takes place in opposite vertical displacements that occurred during the directions in the two intervals considered, while intervals between the first and second and the second and third series of levellings. Diagrams are drawn representing these displacements along nearly straight portions of the levelling route. One of them is reproduced in Fig. 1, in which the small black dots indicate the displacements during the first interval and the small circles those during the second. It is clear from this and similar diagrams (i) that the points lie nearly on segments of straight lines, and (ii) that the ends of these segments lie on the same ordinates for both series of graphs. These features are well explained on the supposition that the crust is made up of a number of blocks, each of which behaves as a nearly rigid body and, at any rate after the earthquake, was able to move with comparative ease apart from its neighbours. The boundaries of the various blocks have been drawn, and it is remarkable how closely they agree with the known fault-lines of the district. Two other points of some interest are also evident from Fig. 1 and other diagrams, namely, (iii) the tilting

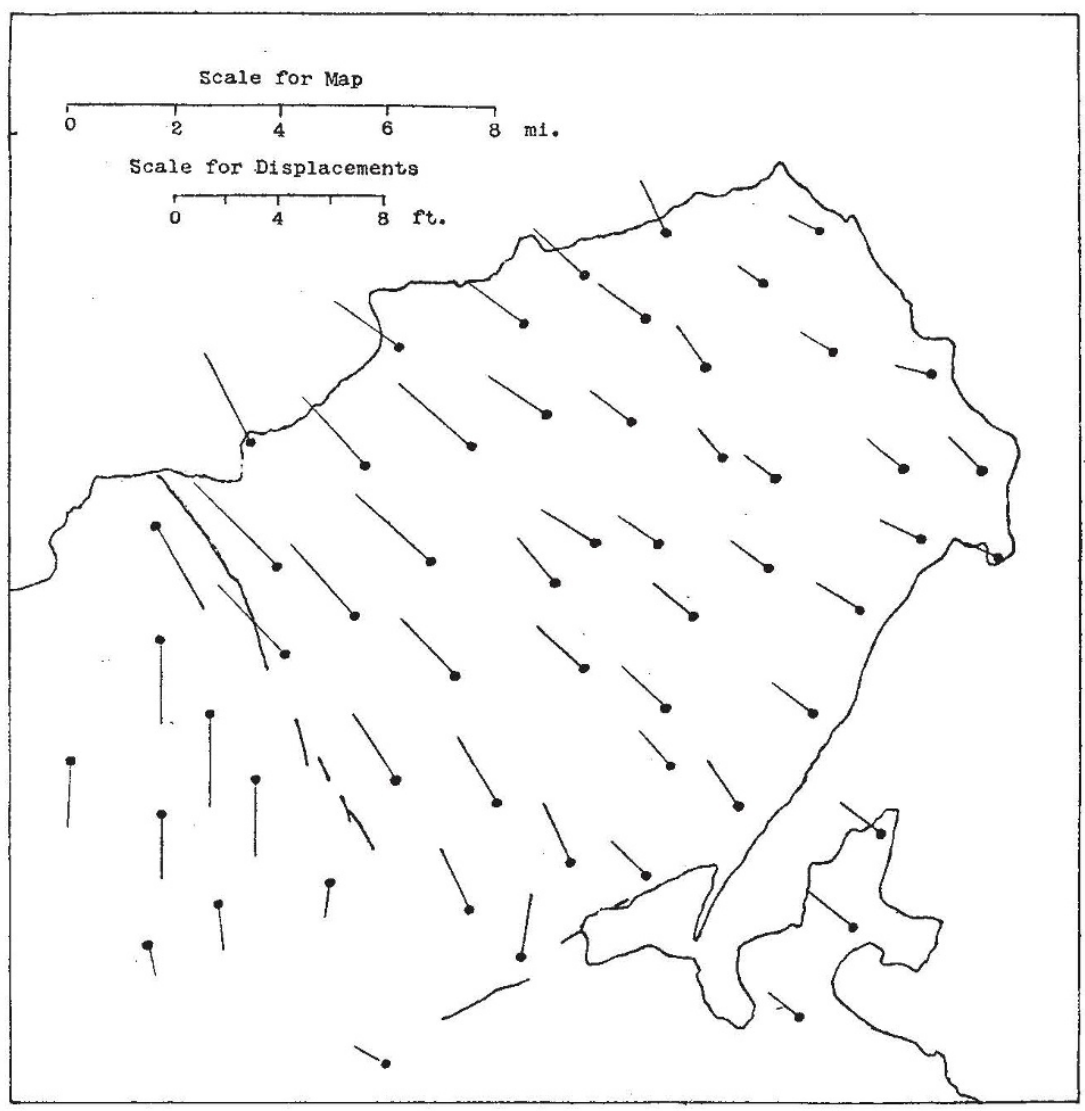

FIG. 2.

No. 3189 , VoL. 126] 
(iv) Fig. 1 shows that two blocks were subjected to a common tilting during the earlier stage but moved separately during the later.

At the time of the earthquake, two remarkable faults were renewed along old lines of dislocation. They are represented by the thick lines in Fig. 2. The Gomura fault, or series of faults, is 11 miles long, and runs in the direction S. $30^{\circ} \mathrm{E}$. along the western boundary of the Oku-Tango peninsula. Relatively to the other side, the crust to the west of the fault was shifted as much as $8 \mathrm{ft} .2 \mathrm{in}$. to the south and uplifted about $1 \mathrm{ft} .8 \mathrm{in}$. The Yamada fault is about $4 \frac{1}{2}$ miles long, and runs in the direction N. $55^{\circ} \mathrm{E}$. along the southern boundary of the peninsula. The crust on the north side of the fault was raised by as much as $2 \mathrm{ft}$. $3 \frac{1}{2} \mathrm{in}$. with respect to that on the other, and shifted $2 \mathrm{ft}$. $7 \frac{1}{2}$ in. to the east.

The main line of levels crosses both faults. The vertical displacements of the bench-marks between 1888 and the first series of levels after the earthquake show that the ground to the west of the Gomura fault has been generally tilted westwards, while the block bounded by the two faults has been tilted to the north by as much as $20^{\prime \prime}$. Similar curves have been drawn for each of the three intervals between successive series of levellings, and it is worthy of notice that, while the curve for each interval differs materially from that up to the first series, the curve representing the total displacements between the first and fourth series resembles it very closely.

No less interesting are the results of the repeated triangulations of the district. Assuming that two points some distance to the south have remained stationary, the displacements of the various points after the fourth triangulation are represented in Fig. 2. From this, it is seen that the mass of the Oku-Tango peninsula has been displaced as a whole, with but slight deformation in itself, in a nearly north-west direction. Maps for the intermediate periods are also given, but they show no tendency to uniformity of displacement like that during the longer interval. One of the most striking features of the map is the discontinuity in the horizontal shifts along the Gomura fault. The greatest displacement measured (of $5 \mathrm{ft} .4 \frac{1}{2} \mathrm{in}$.) occurred at Asago, close to the Gomura fault. At two points, Simooka and Yosizawa, one on either side of the fault, displacements of $4 \mathrm{ft}$. $\mathrm{l}$ in. and $3 \mathrm{ft} .7$ in. occurred in opposite directions nearly parallel to one another and to the fault. The sum of these amounts (7 ft. $8 \mathrm{in}$.) does not differ much from the total shift of $8 \mathrm{ft} .2 \mathrm{in}$. observed in a neighbouring portion of the fault.

C. Davison.

\section{Obituary.}

Prof. Paul Appell.

$\mathrm{O}^{\mathrm{F}}$ the three eminent mathematicians who dominated French science at the beginning of this century, Paul Appell, who died on Oct. 23, aged seventy-five years, will pass down to posterity as an analyst of genius, whose personal charm was equal to the excellence of his teaching. Together with Henri Poincaré, whose mathematical achievements have still to find their equal, and Emile Picard, whom destiny has now left alone to represent the glory of his generation, Paul Appell has laid the foundations upon which a succession of research students and mathematicians have built. Indeed, his masterly "Traité de Mécanique Rationnelle" (1893-1896) maintains its position as a standard text, side by side with the "Traité d'Analyse" of Picard, and the "Méthodes Nouvelles de la Mécanique Céleste " of Poincaré.

Many of our own text-books on pure and applied mathematics still use Appell's lucid demonstrations of difficult problems, such as, for example, the finding of the area of a closed surface, or of the area swept by a moving line, on which is based the theory of the planimeter. But Appell went further than that in his wonderful work : guided by a remarkable intuition, he developed in unusual directions some of the subtlest parts of mechanics, although no experiments of that time could be quoted in support of his views. So he prepared the way for Einstein, whose theories he confirmed later in a supplementary volume on mechanics which he wrote in collaboration with his former pupil, Prof. Thiry.

The fundamental ideas of Paul Appell on higher analysis, which are scattered in a large number of monographs and contributions to learned publications, can be found in his "Théorie des Fonctions Algébriques et de leurs Intégrales " (1895), written in collaboration with Prof. Goursat, and in his "Principes de la Théorie des Fonctions Elliptiques" (1897), written in collaboration with Dr. Lacour. Functions of an analytic point, series and definite integrals, periodic functions and functions of several variables, differential equations and their invariants, equations with partial derivatives, and the theory of potentials, are among the abstruse questions which he attacked successfully; and one should not forget his brilliant memoir on higher analysis, with which he secured the second prize in the international mathematical competition organised in 1889 by the King of Sweden, when Poincaré carried the honours of the day.

It is, however, with his thesis on pure geometry that Appell began his mathematical career in 1876 , when he generalised the notion of involution discovered by Chasles, and made some remarkable applications of it in the theory of cubics. He was then awarded the degree of Doctor of Science and became lecturer in mathematics at the University of Dijon. In 1881 Appell was appointed to the chair of applied mathematics at the École Normale Supérieure in Paris, and in 1885 he was awarded the Prix Bordin for his memoir on the solution of a special problem first suggested by Monge.

In 1892 Appell was elected to the Paris Academy of Sciences, and in 1903 he became Dean of the Faculty of Science, and, soon after, a member of the Higher Education Council, in which capacity he exercised a far-reaching influence over the whole field of university education in France. In 1920 he

No. 3189 . VoL. 1261 